\title{
A CONTABILIDADE SOCIOAMBIENTAL: UM OLHAR SOBRE O SISTEMA CONTÁBIL DE GESTÃO E AS DIRETRIZES DO MEC
}

\section{ARTIGO ORIGINAL}

SARDEIRO, Luciana da Silva Moraes ${ }^{1}$, SILVA, Kaíssyla Maria Ferreira², SILVA, Valdir Sardeiro da ${ }^{3}$

SILVA, Valdir Sardeiro da. SILVA, Kaíssyla Maria Ferreira. SARDEIRO, Luciana da Silva Moraes. A contabilidade socioambiental: um olhar sobre o sistema contábil de gestão e as diretrizes do MEC. Revista Científica Multidisciplinar Núcleo do Conhecimento. Ano 06, Ed. 07, Vol.07, pp. 21-48. Julho de 2021. ISSN: 2448-0959, Link de acesso:

https://www.nucleodoconhecimento.com.br/contabilidade/diretrizes-do-mec, DOI: 10.32749/nucleodoconhecimento.com.br/contabilidade/diretrizes-do-mec

\section{RESUMO}

Tendo em vista que, no Brasil, os estudos relacionados à sustentabilidade e a responsabilidade social vem tendo como foco as organizações, com poucos estudos aplicados em instituições de ensino superior, esse artigo tem como objetivo analisar e avaliar parâmetros de Responsabilidade Socioambiental em uma instituição de ensino superior localizada na Amazônia Legal. Desta forma, para a realização deste trabalho utilizou-se como metodologia a pesquisa exploratória. Os resultados obtidos revelaram que a instituição em análise possui um nível baixo de sustentabilidade, mesmo atendendo os requisitos legais relacionados à responsabilidade socioambiental exigidos pelo Ministério da Educação. Sendo assim, as implicações deste estudo apontam para reflexões em torno das estratégias e práticas da

\footnotetext{
${ }^{1}$ Doutoranda em Contabilidade no PPGCont UnB, Mestre em Planejamento e Gestão Ambiental -Universidade Católica de Brasília. Professora na Universidade Federal Rural da Amazônia - UFRA no Curso de Ciências Contábeis e Administração.

${ }^{2}$ Bacharel em Ciências Contábeis pelo Centro Univ. Norte do Brasil - UniBRAS/ITPAC. Profissional Contábil.

${ }^{3}$ Bacharel em Ciências Contábeis pelo Centro Univ. Norte do Brasil - UniBRAS/ITPAC. Profissional Contábil.
}

RC: 91385

Disponível em: https://www.nucleodoconhecimento.com.br/contabilidade/diretrizesdo-mec 
instituição e para um olhar mais crítico no âmbito da legislação e da avaliação (SINAES) federal socioambiental incidente sobre a educação superior. Este último ponto poderá ser aprimorado em investigações posteriores.

Palavras-chave: Sustentabilidade, Contabilidade, Responsabilidade Social, Ensino Superior, MEC.

\section{INTRODUÇÃO}

A questão socioambiental vem sendo demandada em diversas esferas, seja nas instituições públicas ou privadas e o segmento do ensino superior tem sido alvo de exigências socioambientais legais, regulatórias e por parte da sociedade. arcabouço jurídico institucional do país no que tange ao ensino superior, assinala a necessidade das Instituições de Ensino Superior - IES, cumprirem um contingente de exigências no que se refere a responsabilidade social, a educação ambiental e a gestão ambiental. Neste sentido, destaca-se a Lei das Diretrizes e Bases da Educação - LDB Lei 9.394 de 1996 a qual assinala a necessidade da formação educacional amparada nas questões sociais e ambientais. A Lei de Educação Ambiental 9.795 de 2001 e a Lei 10.861 de 2004 estabelecem as diretrizes para o SINAES - Sistema Nacional de Avaliação do Ensino Superior que contêm critérios relativos à responsabilidade social, a gestão ambiental e a educação ambiental dentre outros quesitos. (BRASIL 2004a, 2016).

Desde 1992 a Agenda XXI da Conferência Mundial de Meio Ambiente, RIO 92 já preconizava a importância da contabilidade na asseguração do desenvolvimento sustentável. O Desenvolvimento Sustentável é conceituado na Agenda XXI como aquele capaz de atender as necessidades das atuais gerações sem comprometer a necessidade das gerações futuras. (BRASIL, 2000)

Autores como Pfitscher (2004) desenvolveram metodologias para avaliar o grau de sustentabilidade no que se refere a contabilidade sob a perspectiva ambiental, identificando aspectos como compras, registros contábeis, relatórios e tomada de 
decisão quanto ao aspecto ambiental que impactam ainda nas questões sociais das organizações.

A região norte do Brasil tem sido alvo de diversas discussões científicas, filosóficas e políticas no que se refere a importância dos serviços ecossistêmicos fornecidos pelo bioma da floresta amazônica. Neste sentido o estudo enfoca uma IES privada sediada nesta região verificando sob a lente da sustentabilidade e da contabilidade as potencialidades para o aprimoramento da responsabilidade socioambiental. A problemática de define no seguinte questionamento: Existem potencialidades a serem aprimoradas no que se refere à gestão da responsabilidade socioambiental sob o enfoque da contabilidade e das diretrizes do Ministério da Educação?

Assim, o objetivo do trabalho foi analisar potenciais fatores a serem aprimorados sob o enfoque do sistema contábil de gestão ambiental e da conformidade legal socioambiental para com o Ministério da Educação (MEC). Enquanto os objetivos específicos foram: diagnosticar os principais aspectos ambientais da IES; identificar - grau de sustentabilidade; comparar os aspectos normativos da área de responsabilidade socioambiental na educação superior com a situação observada na instituição; e expender acerca dos aspectos a serem potencializados.

A relevância do estudo se ancora na importância do tema para a coletividade tendo em vista que a questão ambiental repercute na saúde, na qualidade de vida das pessoas e no equilíbrio da manutenção dos ecossistemas. (BURRITT; HAHN; SCHALTEGGE, 2000; MAY et al., 2018). Outra justificativa é consubstanciada nos fundamentos constitucionais, pois o meio ambiente equilibrado é direito de todos. Do ponto de vista do enfoque social evidencia-se o fato de que a região norte, local de realização do estudo, apresenta os piores indicadores no que se refere à desigualdade social no país segundo Otonielli et al (2014) e Silva (2016) e esta situação se mantem há décadas de acordo com os estudos. A exclusão social, as condições de produção e reprodução da pobreza potencializam os problemas ambientais. Sachs (1986) alerta que "a degradação ambiental agrava as condições de vida dos mais pobres, a pobreza destes conduz a uma exploração predatória dos 
recursos naturais, fechando um ciclo perverso de prejuízos socioambientais" (SACHS, 1986).

Outro aspecto que evidencia a relevância do estudo são as exigências legais e normativas no tange aos aspectos socioambientais junto ao Ministério da Educação Brasileiro a exemplo do Plano de Desenvolvimento Institucional - PDI que é um dos principais documentos a serem analisados por parte dos avaliadores do Ministério da Educação no processo de credenciamento, transformação, autorização e reconhecimento de instituições e nos processos de autorização, renovação e reconhecimento de cursos no ensino superior. Através do PDI as IES são cobradas por sua atuação relativa à responsabilidade social, a diversidade, ao meio ambiente, à memória cultural, à produção artística e ao patrimônio cultural dentre outros aspectos. O PDI constitui-se como um conjunto de diretrizes filosóficas, pedagógicas, gerenciais e operacionais das instituições conforme a Lei 10.861 de 2004, Decreto 5.773 de 2006 e Portaria número 92 de 2016. (BRASIL, 2004a, 2016).

A metodologia de análise da sustentabilidade e da responsabilidade socioambiental proposta especificamente neste estudo não foi testada na região norte, pois a parcela mais significativa dos estudos envolvendo a temática e metodologia abordada, a exemplo da utilização da análise de sustentabilidade com o uso do SICOGEA - Sistema de Contabilidade da Gestão Ambiental, concentra-se na região sul e sudeste do Brasil conforme demonstrado nas publicações discutidas no referencial teórico por meio da Professora Pfitscher e seus coautores referendados na bibliografia deste estudo. (PFITSCHE et al., 2008, 2009, 2011, 2012, 2013)

\section{REFERENCIAL TEÓRICO}

A pirâmide da responsabilidade social desenvolvida por Carrol (1979) sustenta que os primeiros autores ao tratarem o tema se reportavam ao conceito como a necessidade que as organizações possuem de produzir bens ou serviços para gerar um equilíbrio econômico e em consequência o bem-estar social. A raiz ideológica desta conceituação é relacionado ao liberalismo smithiano. Na fase posterior, a 
responsabilidade social era vinculada ao cumprimento da legislação e ao dever ético, estar em conformidade com a lei em seus amplos aspectos denotaria o caráter e perfil responsável das organizações. Na terceira fase a responsabilidade voluntária, se atrela de forma cumulativa a responsabilidade econômica, ética, legal e ao mesmo tempo assumir papeis de mudança na sociedade de forma a buscar a modificação do contexto social. (CARROL, 1979; BASTOS e LIMA, 2016). No Quadro 01, Bastos e Lima (2016) adaptam um quadro conceitual acerca da responsabilidade social desenvolvido a partir dos estudos de Carrol:

Quadro 01 - Concepções de Responsabilidade Social e Autores

\begin{tabular}{l|l} 
Principal contribuição & Autores \\
\hline Garantir unicamente os lucros & Friedman \\
\hline $\begin{array}{l}\text { Aplicar o conceito de RSC mediante } \\
\text { requisitos econômicos e legais }\end{array}$ & McGuire \\
\hline $\begin{array}{l}\text { Promover atividades voluntárias } \\
\text { Promover atividades voluntárias, } \\
\text { econômicas e legais }\end{array}$ & Steiner \\
\hline Aplinne
\end{tabular}

Aplicar círculos concêntricos cada vez CED - Comittee for Economic maiores Development, Davis e Blomstrom

Ter preocupação mais ampla com o Eells e Walton sistema social

Demonstrar a responsabilidade como um Hay, Gray e Gates número de problemas sociais

Fornecer um caminho para a Ackerman e Bauer, Sethi responsabilidade social

Fonte: Carrol (1979) adaptado por Bastos e Lima (2016)

As concepções do quadro 1 variam do pragmatismo do economista Milton Friedman que afirma que a Responsabilidade Social da Empresa é garantir lucros, à abordagem legal de cumprimento da legislação com McGuire, ao voluntariado com 
Manne e Steiner, a atuação social do CED - Comitee for Economic Development, Davis e Blomstrom e Eells e Walton e a ampliação da abrangência de atuação da empresa para abordagens em que se demonstra a responsabilidade social das organizações com Hay, Gray e Gates à construção de novas perspectivas da para a sociedade como Ackerman, Bauer e Sethi. (CARROL, 1979).

Barakat et al. (2017) cita estudos como DeBakker; Groenwegen; DenHond (2005) as quais descrevem que o tema responsabilidade social corporativa - RSC está em desenvolvimento:

\begin{abstract}
A RSC é ainda considerada um campo de pesquisa em desenvolvimento. DeBakker, Groenwegen e DenHond (2005) realizaram uma análise bibliométrica de mais de 500 artigos sobre RSC publicados nos últimos 35 anos e concluíram que não é possível evidenciar uma operacionalização dos conceitos gerais centrais. O desenvolvimento do construto de RSC é caracterizado por três aspectos distintos: progressão, variedade e normativismo. A progressão significa que 0 construto foi desenvolvido a partir da teoria empiricamente testada. A variedade explica que o conceito alterna seu significado de acordo com o contexto ou com a relação que estabelece com temas complementares. E, finalmente, o normativismo refere-se ao caráter prescritivo encontrado nos trabalhos nesse campo (BARAKAT; BOAVENTURA; POLO, 2017).
\end{abstract}

Melo Neto e Brennand (2004, p. 39) sustentam que "uma empresa socialmente responsável é aquela que investe no bem-estar de seus funcionários e dependentes e num ambiente de trabalho saudável, além de preservar o meio ambiente e investir em ações sociais".

O conceito de Sustentabilidade é oriundo do Relatório chamado "The Bundtl and Report' escrito pela World Comissionon Environment and Development em 1987, que traz o conceito de desenvolvimento sustentável como sendo aquele capaz de suprir as condições de vida das atuais gerações sem que o modo de vida comprometa as gerações vindouras (BRUNDTLAND, 1987). Elkington (2012) em seguida cria o temo Triplo Botton Line (TBL) adaptando o desenvolvimento sustentável (DS) ao mundo dos negócios. Segundo o referido autor o DS se ancora 
em três aspectos, a busca pela equidade social, pelo crescimento econômico e pelo equilíbrio ambiental.

Em 1998 o programa das Nações Unidas publicou um documentos intitulados Enviromental Financial Accounting and Reporting at the Corporate Level (1998), o documento continha capítulos que tratavam da relação da contabilidade e do meio ambiente, desde os custos às contas nos demonstrativos contábeis. (NAÇÕES UNIDAS 1998). Apesar disso, os atuais estudos que envolvem a contabilidade constam a pouca evolução da contabilidade ambiental no reporte das companhias, seja pelo caráter voluntário, falta de conhecimento ou vontade política das organizações e reguladores (NEGASH, 2012; DEGAN, 2017; SARDEIRO w SOUZA, 2021; SARDEIRO e BILHIM, 2021)

Um dos modelos de reporte socioambiental mais utilizados no mundo é o padrão Global Reporting Iniciative (GRI) que congrega indicadores de natureza econômica, social e ambiental.

A Global Reporting Initiative (GRI) é um processo internacional de longo prazo e multi partite cuja missão é desenvolver e divulgar as Diretrizes de Relatórios Sustentáveis aplicáveis a nível mundial (" Diretrizes "). Essas Diretrizes são para uso voluntário por organizações para informar sobre as dimensões econômicas, ambientais e sociais de suas atividades, produtos e serviços. (GLOBAL REPORTING INICIATIVE - GRI, 2002)

As Nações Unidas publicam em 2001 um novo documento "Contabilidade da Gestão Ambiental Procedimentos e Princípios", produzido pela colaboração de diversos contadores em todo o mundo. O documento apresenta em riqueza de detalhes uma metodologia de como implementar um processo de gestão ambiental articulado com a contabilidade de modo a enfocar o uso racional dos recursos. Desde da matériaprima à gestão das emissões em uma perspectiva de mensuração, registro e monitoramento da gestão ambiental. (NAÇÕES UNIDAS, 2001).

Para além das pesquisas que se limitam a análise de relatórios voluntários com contribuições limitadas em termos contábeis conforme evidenciam Gray e Milne 
(2015, p. 22), a contabilidade ambiental necessita de assumir uma responsabilidade radical evocada por Owem (2014). Owem afirma que se nós contadores não agirmos de forma ética alinhada aos valores socioambientais, os banqueiros e os valores compartilhados no mercado não o farão.

Gray (1993) elucida os amplos aspectos que podem ser pautas da contabilidade ambiental, desde o custo sustentável que se ocupa de mensurar os aspectos ambientais no cotidiano das organizações até a mensuração das externalidades socioambientais ou até mesmo do capital natural.

Freire; Botelho e Nunes (2001) trazem a concepção do Balanço Social (BS), segundo os autores o BS é uma metodologia para o reporte da responsabilidade socioambiental da empresa para com o seu meio, seja funcionários, clientes, comunidade e demais stakeholders. Mazzioni; Tinoco e Oliveira (2007) discutiram a evidenciação socioambiental no âmbito das instituições de ensino superior atentando às suas especificidades. Na produção de Seiffert (2007) discute que o processo de gestão ambiental só pode ter continuidade por meio das estratégias de educação ambiental afim de que se sustente a longo prazo.

A bolsa de valores brasileira (B3) possui o Índice de Sustentabilidade (ISE) desde 2011 e em 2012 adotou a metodologia praticada na bolsa sul africana "Relate ou Explique", em que as companhias que não realizam o reporte socioambiental devem explicar o porquê da opção. Atualmente a B3 integra outros programas de vertente socioambiental dentre os quais a adoção dos padrões Environmental, Social and Governance (ESG), o qual possui parâmetros para avaliar desde a governança às questões socioambientais com parâmetros praticados internacionalmente (B3, 2021).

Já o SICOGEA - Sistema de Contabilidade da Gestão Ambiental é oriundo do trabalho da pesquisadora Professora Dr. Pfitscher no ano de 2004. O modelo desenvolvido pela estudiosa aborda a perspectiva do mapeamento dos eventos econômicos derivados dos aspectos ambientais relacionados aos clientes e 
fornecedores das informações contábeis em seguida a Gestão e Controle Ecológico. O modelo verifica a gestão dos processos que visam resguardar a salvaguarda dos recursos naturais e a Gestão da Contabilidade e Controladoria Ambiental relativos aos aspectos operacionais repercutidos na contabilidade e finanças das organizações, conforme aborda o quadro 02 (PFITSCHER, 2004, p. 102).

Quadro 02 - Etapas do Modelo SIGOGEA

\section{Etapas da Descrição}

Proposta

Integração da Envolvimento da cadeia produtiva. Alinhamento da cadeia de cadeia suprimentos envolvendo a identificação das necessidades dos clientes e fornecedores. Pode também ser considerado o input para o processo de gestão ambiental, ou seja, verificar as degradações causadas em cada atividade e sua formatação como um evento econômico.

Gestão de Implementação da gestão ecológica e dos processos para a controle certificação e envidar esforços no sentido de reduzir ou eliminar ecológico impactos ambientais.

Gestão da Avaliação dos efeitos ambientais capazes de relacionar contabilidade/ aspectos operacionais, econômicos e financeiros da gestão Controladoria ambiental (investigação e mensuração); avaliação dos setores da empresa (informação) e implementação de novas alternativas para continuidade do processo (decisão).

Fonte: Pfitscher, (2004) em Ferreira (2002)

Alguns dos estudos anteriores sobre a aplicação e investigação da metodologia SICOGEA que está em sua terceira geração foram explicitados nas pesquisas abaixo no Quadro 03 abordando segmentos diferenciados. 
Quadro 03 - Pesquisas e Metodologia SICOGEA

\section{Fontes}

Limongi; Kremer; Casagrande;

Pfitscher; Nunes (2008)

Baldissera, Alves; Farias, ; Costa; Setor de Serviços - Lavanderia

Pfitscher, (2008)

Freitas; Silveira; Richartz; Pfitscher; Setor Alimentício- Indústria de Sucos

Brenner; Zolet, (2008)

Cunha; Casagrande; Pfitscher; Setor Público - Estação de Tratamento de

Limongi; Ceolato, (2008)

Rosa; Pfitscher; Silva; Vieira, (2008)

Sousa; Tavares; Pfitscher (2008)

Nascimento; Gatlc

Nunes; Limong; Pfitscher; Setor Industrial - Fábrica de Pranchas de

Carrascoza (2008)

Pfitscher; Nunes; Furtado, (2008)

Richartz; Freitas; Pftscher (2009)

Ramalho; Pfitscher; UhImann; Setor de Saúde - Odontológico

Rabelo (2010)

Pierre; Pfitscher; Frey; Freitas

Starosky Filho; Pfitscher; Freitas (2011)

Keunecke, UhImann, Pfitscher (2012)

Bacelo; Uhlmann; Pfitscher; Souza Setor de Serviços - Condomínios
Esgoto

Setor Alimentício - Rede de Supermercados

Setor de Serviços - Empresa Aérea Brasileira Surfe.

Setor Industrial - Fabricação de Cerâmica

Setor Industrial - Indústria de Bebidas

Setor de Educacional- Universidade Comunitária

Setor de Serviços - Escritório de Contabilidade

Instituição de Ensino Superior Pública Federal

Disponível em: https://www.nucleodoconhecimento.com.br/contabilidade/diretrizes$\underline{\text { do-mec }}$ 
(2011)

Kruger; Pfitscher; Uhlmann; Petri Setor de Educacional - Instituição de (2013) Ensino Pública

Vegini; Pfitscher; Nunes e Rosa Setor de Serviços - Hospital Público (2008)

Souza e Pfitscher (2013)

Setor de Serviços - Energia Elétrica

Fonte: Adaptado pelos autores a partir da produção de Pfitsche et al 2008, 2009, 2011, 2012, 2013)

A exigência quanto a responsabilidade socioambiental nas IES pode ser verificada nos instrumentos do Sistema Nacional de Avaliação do Ensino Superior - SINAES de responsabilidade do Instituto Nacional de Educação e Pesquisa Anísio Teixeira INEP vinculado ao Ministério da Educação - MEC. O SINAES no instrumento de avaliação das IES possui cinco eixos de avaliação e dez dimensões a serem averiguadas. Os eixos da avaliação das instituições de ensino superior são: Planejamento e Avaliação institucional; Desenvolvimento Institucional; Políticas Acadêmicas; Políticas de Gestão e Infraestrutura. Já as dimensões são:

1.A missão e o Plano de Desenvolvimento Institucional; 2. A política para o ensino, a pesquisa, a pós-graduação, a extensão e as respectivas normas de operacionalização, incluídos os procedimentos para estímulo à produção acadêmica, as bolsas de pesquisa, de monitoria e demais modalidades; 3 . A responsabilidade social da instituição, considerada especialmente no que se refere à sua contribuição em relação à inclusão social, ao desenvolvimento econômico e social, à defesa do meio ambiente, da memória cultural, da produção artística e do patrimônio cultural; 4. A comunicação com a sociedade; 5. As políticas de pessoal, de carreiras do corpo docente e corpo técnico-administrativo, seu aperfeiçoamento, desenvolvimento profissional e suas condições de trabalho 6.Organização e gestão da instituição, especialmente o funcionamento e representatividade dos colegiados, sua independência e autonomia na relação com a mantenedora, e a participação dos segmentos da comunidade universitária nos processos decisórios 7. Infraestrutura física, especialmente a de ensino e de pesquisa, biblioteca, recursos de informação e comunicação; 8. Planejamento e avaliação, especialmente em relação aos processos, resultados e eficácia do autoavaliação institucional; 9. Políticas de atendimento aos estudantes; 10.

RC: 91385

Disponível em: https://www.nucleodoconhecimento.com.br/contabilidade/diretrizesdo-mec 
Sustentabilidade financeira, tendo em vista o significado social da continuidade dos compromissos na oferta da educação superior. (BRASIL, 2014)

Conforme observado, a dimensão três trata da responsabilidade social no que se refere ao desenvolvimento socioeconômico, à inclusão, cultura e meio ambiente; na dimensão cinco, aborda o aspecto social no que tange as políticas de pessoal incluindo o registro, jornada de trabalho e programas de incentivo; na dimensão dez a sustentabilidade financeira relacionada a continuidade da instituição.

Já a Lei de Diretrizes e Bases da Educação n॰9.394 de 1996 preconiza em seu art. 26 a imposição da articulação dos currículos em diferentes aspectos e dentre estes o contexto ambiental. A lei no9.705 de 1999 institui a obrigatoriedade da Educação Ambiental no âmbito formal e informal, seja em escolas, universidades, repartições públicas e instituições privadas.

Além das imposições legais supracitadas, o Plano Nacional de Educação também se coaduna com o marco legal da responsabilidade socioambiental e da gestão ambiental no Brasil. O atual Plano Nacional de Educação - PNE, com vigência até o ano 2024 tem como objetivos prioritários diferentes estratégias, dentre o elenco de propósitos estão a melhoria da qualidade da educação e a promoção dos princípios do respeito aos direitos humanos, à diversidade e à sustentabilidade socioambiental. Assim ao abordar a sustentabilidade engloba a gestão ambiental e social das instituições de ensino.

Conforme observado, as Instituições de Ensino Superior - IES vem sendo paulatinamente cobradas num amplo marco regulatório no que se refere ao ensino superior e sua inserção proativa na construção da sustentabilidade, responsabilidade social e gestão ambiental. (BRASIL, 2014)

\section{MATERIAL E MÉTODOS}

Quanto ao aspecto metodológico acerca da abordagem do conhecimento o método definido nesta pesquisa possui uma abordagem dialética, pois trata-se de uma 
investigação que se propõe a compreensão, interpretação da realidade de modo a futuramente orientar as ações sobre a realidade. $O$ estudo se debruça no investigar e constituir as linhas para futuras interações com a realidade social construída. Conforme Loureiro (2007), na visão de sociedade, natureza e mundo, não há como separar o homem da natureza, pois trata-se de uma realidade complexa e dinâmica e muito contrária do que se imagina. Como afirma Lefebvre (1966) o "homem diferencia-se da natureza, não se separa dela. Assim, tal abordagem se configura na perspectiva para além da retratação diagnóstica e se constitui em análise e proposição acerca da mudança social" (LEFEBVRE, 1966).

A pesquisa é do tipo aplicada e quanto a problemática é classificada como qualitativa uma vez que envolve a interpretação da realidade apresentada. O método procedimental é caracterizado como estudo de caso a ser desenvolvido em uma instituição de ensino superior privada. Quanto aos objetivos é classificada como exploratória uma vez que busca familiaridade com o tema e faz uso de estratégias como entrevistas e pesquisa bibliográfica. $O$ estudo foi realizado em uma instituição de ensino superior situada na Amazônia Legal. O período de elaboração da proposta de pesquisa à realização da investigação ocorreu de maio de 2016 a julho 2017 sendo a autorização junto pelo CEP - Comitê de Ética e Pesquisa realizada pelo Parecer Consubstanciado número: 1.767.656 de ocorreu no dia 18 de outubro de 2016.

Os instrumentos técnicos para coleta de dados descritos no quadro 04 , evidenciam a relação entre os objetivos e os instrumentos:

Quadro 04 - Objetivos e Instrumentos Técnicos de Coleta de Dados

Fontes

Limongi; Kremer; Casagrande;

Pfitscher; Nunes (2008)

Baldissera, Alves; Farias, ; Costa; Setor de Serviços - Lavanderia Pfitscher, (2008)

\section{Segmentos}

Setor de Educacional - Escola/Educação Infantil ao Ensino Médio 
Freitas; Silveira; Richartz; Pfitscher; Setor Alimentício- Indústria de Sucos

Brenner; Zolet, (2008)

Cunha; Casagrande; Pfitscher; Setor Público - Estação de Tratamento de

Limongi; Ceolato, (2008)

Rosa; Pfitscher; Silva; Vieira, (2008) Esgoto

\begin{tabular}{|l|ll} 
Rosa; Pfitscher; Silva; Vieira, (2008) & $\begin{array}{l}\text { Setor Alimentício - Rede de } \\
\text { Supermercados }\end{array}$ \\
Sousa; Tavares; Pfitscher (2008) & $\begin{array}{l}\text { Setor de Serviços } \\
\text { Brasileira }\end{array}$ &
\end{tabular}

Nascimento; Gallon; Gasparetto; Setor Rural - Atividade Aquícola.

Pfitscher, (2008)

Nunes; Limong; Pfitscher; Setor Industrial - Fábrica de Pranchas de

Carrascoza (2008) Surfe.

Pfitscher; Nunes; Furtado, (2008)

Setor Industrial - Fabricação de Cerâmica

Richartz; Freitas; Pftscher (2009)

Setor Industrial - Indústria de Bebidas

Ramalho; Pfitscher; Uhlmann; Setor de Saúde - Odontológico

Rabelo (2010)

Pierre; Pfitscher; Frey; Freitas

Setor de Educacional- Universidade Comunitária

Starosky Filho; Pfitscher; Freitas Setor de Serviços - Escritório de (2011) Contabilidade

Keunecke, UhImann, Pfitscher Instituição de Ensino Superior Pública (2012) Federal

Bacelo; UhImann; Pfitscher; Souza Setor de Serviços - Condomínios (2011)

Kruger; Pfitscher; UhImann; Petri Setor de Educacional - Instituição de (2013) Ensino Pública

Vegini; Pfitscher; Nunes e Rosa Setor de Serviços - Hospital Público (2008)

Souza e Pfitscher (2013)

Setor de Serviços - Energia Elétrica

Fonte: Elaborado pelos autores

RC: 91385

Disponível em: https://www.nucleodoconhecimento.com.br/contabilidade/diretrizesdo-mec 
Os aspectos ambientais foram observados quanto ao objetivo específico inicial como detalhamento dos aspectos a serem potencializados para que complemente as informações trazidas pela metodologia SICOGEA. Já os aspectos normativos são exigidos pela legislação federal ambiental e pela legislação que trata da avaliação das instituições de ensino superior e que, portanto, possui aspectos idiossincrásicos não atendidos pela metodologia SICOGEA. Para aplicação da metodologia de investigação do SICOGEA utilizou-se a lista de verificação desenvolvida por Pierri (2010), a qual possui 154 questões para análise da sustentabilidade ambiental das instituições de ensino, as quais foram adaptadas para que pudessem ser aplicadas à instituição analisada.

A partir dessa lista de verificação, realizou-se a aplicação de entrevistas com base em um questionário aos responsáveis de diversos setores da universidade, tais como a Direção, Setor de Manutenção e Obras, Coordenação de Recursos Humanos, Programa de Atendimento ao Aluno, Setor de Apoio, Setor de Compras, Setor de Contabilidade; além de análise documental realizada pelo pesquisador, visando identificar as práticas sociais e ambientais da instituição. O Quadro 05 aponta os respondentes em cada critério analisado.

Quadro 05 - Respondentes por critérios analisados

Critérios analisados

Critério 1 - Fornecedores/compras

Critério 2 - Ecoeficiência do processo de Engenheiro e Setor de Apoio prestação de serviço

Critério 3 - Prestação do serviço - atendimento Setor de Atendimento ao Aluno ao acadêmico

Critério 4 - Responsabilidade social na Dirigentes instituição

Critério 5 - Gestão estratégica da instituição Dirigentes

Critério 6 - Indicadores gerenciais
Respondentes

Setor de compras

Diretoria Adm. Financeira 


\begin{tabular}{|l|l|}
\hline Critério 7 - Recursos humanos na instituição & Setor de RH \\
\hline Critério 8 - Indicadores contábeis & Contabilidade \\
\hline $\begin{array}{l}\text { a) indicadores ambientais de bens e direitos e } \\
\text { obrigações }\end{array}$ & Contabilidade \\
\hline $\begin{array}{l}\text { b) indicadores ambientais de contas de } \\
\text { resultados }\end{array}$ & Contabilidade \\
\hline $\begin{array}{l}\text { c) indicadores de demonstração ambiental } \\
\text { específica }\end{array}$ & Contabilidade \\
\hline Critério 9 - Auditoria ambiental & $\begin{array}{l}\text { Setor de Apoio e Engenheiro } \\
\text { Responsável }\end{array}$ \\
\hline Total de questões & 154 \\
\hline
\end{tabular}

Fonte: Dados da pesquisa

A partir das 154 respostas da lista de verificação, coletadas durante o mês de janeiro a junho de 2017, uma análise de abordagem qualitativa das questões foi realizada sob as escalas de 0 a 5 ou $0 \%$ a $100 \%$, onde:

- 0 ou $0 \%$ : nível nulo de investimentos e ações ambientais;

- 1 ou $20 \%$ : nível baixo de investimentos ou controles ambientais;

- 2 ou $40 \%$ : nível um pouco acima que investimento anterior;

- 3 ou $60 \%$ : nível médio de investimentos e controles ambientais;

- 4 ou $80 \%$ : nível um pouco abaixo do alto nível de investimentos e controles ambientais;

- 5 ou $100 \%$ : nível alto de investimentos e controles ambientais.

Para o cálculo da sustentabilidade ambiental utilizou-se a seguinte fórmula conforme Quadro 06: 
Quadro 6 - Fórmula do cálculo da sustentabilidade

\begin{tabular}{|ll|}
\hline Índice geral de sustentabilidade: & Pontos alcançados \\
\hline
\end{tabular}

Fonte: Bacelo et al. (2011, p. 113)

Com a aplicação da fórmula do cálculo da sustentabilidade, tanto o índice específico de sustentabilidade ambiental de cada um dos 9 parâmetros avaliados pelo SICOGEA (Geração III) quanto o índice geral de sustentabilidade ambiental da instituição de ensino em questão, puderam ser identificados.

A Tabela 1 apresenta a classificação e interpretação de cada percentual que pode ser obtido, conforme o SICOGEA.

Tabela 1 - Avaliação da sustentabilidade e desempenho ambiental segundo o SICOGEA

\begin{tabular}{|c|c|c|}
\hline Resultado & Sustentabilidade & Desempenho: controle, incentivo, estratégia \\
\hline $\begin{array}{l}\text { Inferior a } \\
20 \%\end{array}$ & Péssima - 'P' & $\begin{array}{l}\text { Pode estar causando grande impacto ao meio } \\
\text { ambiente }\end{array}$ \\
\hline $\begin{array}{l}\text { Entre } 21 \mathrm{e} \\
40 \%\end{array}$ & Fraca - 'F' & $\begin{array}{l}\text { Pode estar causando danos, mas surgem algumas } \\
\text { poucas iniciativas }\end{array}$ \\
\hline $\begin{array}{l}\text { Entre } 41 \text { e } \\
60 \%\end{array}$ & Regular - 'R' & Atende somente à legislação \\
\hline $\begin{array}{l}\text { Entre } 61 \text { e } \\
80 \%\end{array}$ & Boa - 'B' & $\begin{array}{l}\text { Além da legislação, surgem alguns projetos e } \\
\text { atitudes que buscam valorizar o meio ambiente }\end{array}$ \\
\hline $\begin{array}{l}\text { Superior a } \\
80 \%\end{array}$ & Ótima - 'O' & $\begin{array}{l}\text { Alta valorização ambiental com produção ecológica } \\
\text { e prevenção da poluição }\end{array}$ \\
\hline
\end{tabular}

Fonte: Pfitscher (2004)

Após a realização e o preenchimento das questões da lista de verificação adaptada de Pierri (2011), cada índice de sustentabilidade e de desempenho ambiental da 
instituição analisada foi avaliada segundo os critérios do SICOGEA (Geração 3), sob os 9 parâmetros propostos por Pierri (2011) para instituições de ensino.

\section{RESULTADOS}

Após a coleta das informações junto aos responsáveis por setores ou departamentos da instituição, seguindo o roteiro da lista de verificação de Pierri (2011), foi possível identificar os índices de sustentabilidade da instituição objeto do estudo, atendendo a nove critérios estabelecidos. A tabela 02 apresenta os índices de sustentabilidade obtidos por critério a partir do SICOGEA - Geração 3.

De acordo com a tabela 02 no que concerne ao critério 1- Fornecedores, observouse que a instituição pode buscar melhorar seus processos de compras instituindo critérios socioambientais na seleção de fornecedores. Um aspecto positivo encontrado neste item foi a priorização de micro e pequenas empresas nas compras de materiais para consumo da IES. Futuramente a IES poderá potencializar a gestão socioambiental priorizando a compra de produtos com maior eficiência energética e menor impacto ambiental. Poderá ainda buscar por fornecedores que estejam comprometidos com o ciclo de vida dos produtos, e possam auxiliar no descarte destes, principalmente os eletrônicos e da construção civil. No segundo critério observado com relação à ecoeficiência de acordo com a metodologia e como aponta os resultados foi classificada como fraca, como aspecto positivo ressalta-se que há um sistema de aproveitamento da água de aparelhos de ar-condicionado em um dos prédios da instituição. Percebe-se que a instituição pode incrementar diversas políticas e prática junto aos setores visando à conscientização da questão ambiental internamente, bem como a padronização de processos mais dispendiosos para aumentar a eficiência e economicidade da instituição.

O critério 3- Prestação de Serviço- atendimento ao acadêmico, observa-se de forma geral que a instituição possui uma infraestrutura física adequada, porém a relação de profissionais para a quantidade de alunos é desproporcional, de acordo com os dados coletados na Tabela 02. 
Já o critério 4 - Responsabilidade social na instituição, foi identificado que existe uma política de Responsabilidade Socioambiental e que existem muitos projetos de extensão que abordam o tema ambiental e social na instituição, porém são desarticulados e os recursos para a pesquisa na área são escassos apesar de existir uma linha de pesquisa na área. Não existe um programa com objetivos, metas e plano de ação para a área socioambiental baseado na realidade local da instituição. São realizados anualmente mais de 360 projetos que abrangem aspectos sociais e ambientais, onde o registro e expedição de certificados do programa ocorre por parte da Coordenação de Extensão. Destaca-se neste sentido as Ligas Acadêmicas nos cursos da área de saúde com um quantitativo expressivo de projetos nesta área.

Tabela 02 - Resultado da lista de verificação - SICOGEA- Geração 3

\begin{tabular}{|c|c|c|c|c|}
\hline \multirow{2}{*}{$\begin{array}{l}\text { CRITÉRIOS } \\
\text { Critério } \quad 1 \\
\text { Fornecedores/compras }\end{array}$} & \multirow{2}{*}{\begin{tabular}{|l}
$\begin{array}{l}\text { Pontos } \\
\text { Possíveis }\end{array}$ \\
18
\end{tabular}} & \multirow{2}{*}{$\begin{array}{l}\text { Pontos } \\
\text { Alcançados } \\
3\end{array}$} & \multicolumn{2}{|c|}{$\begin{array}{l}\text { Sustentabilidade } \\
\text { Índice e Avaliação }\end{array}$} \\
\hline & & & $18,75 \%$ & Péssima \\
\hline $\begin{array}{l}\text { Critério } 2 \text { - Ecoeficiência do } \\
\text { processo de prestação de } \\
\text { serviço }\end{array}$ & 68 & 22,8 & $33,53 \%$ & Fraca \\
\hline $\begin{array}{lll}\text { Critério } 3 \text { - Prestação do } & \text { do } \\
\text { serviço - atendimentos } & \text { ao } \\
\text { acadêmico } & & \end{array}$ & 13 & 7,2 & $55,38 \%$ & Regular \\
\hline $\begin{array}{l}\text { Critério } 4 \text { - Responsabilidade } \\
\text { social na instituição }\end{array}$ & 18 & 3,6 & $14,40 \%$ & Péssima \\
\hline $\begin{array}{l}\text { Critério } 5 \text { - Gestão estratégica } \\
\text { da instituição }\end{array}$ & 16 & 11 & $61,11 \%$ & Boa \\
\hline $\begin{array}{l}\text { Critério } 6-\text { Indicadores } \\
\text { gerenciais }\end{array}$ & 16 & 9,9 & $61,88 \%$ & Boa \\
\hline Critério 7 - Recursos humanos & 23 & 10,4 & $45,22 \%$ & Regular \\
\hline
\end{tabular}




\section{na instituição}

Critério 8 - Indicadores

contábeis

a) indicadores ambientais de 18 bens e direitos e obrigações

b) indicadores ambientais de 10

$1 \quad 10,00 \%$ Péssima contas de resultados

c) indicadores

demonstração

de 10

3

$30,00 \%$ Fraca

específica

Critério 9 - Auditoria ambiental

Total Geral da Instituição

ambiental

Fonte: Elaborado pelos Autores

Os critérios 5 e 6 - Gestão Estratégica e Indicadores Gerenciais, observa-se que apesar de haver a previsão orçamentária para a questão socioambiental ainda não existe um programa de gerenciamento da responsabilidade socioambiental apoiado em objetivos, metas e plano de ação. A questão socioambiental está presente nos projetos pedagógicos, no contexto de algumas disciplinas em cada curso, porém ainda não faz parte de um processo formal de sensibilização e gestão profissionalizada dos processos socioambientais. Verifica-se que os dirigentes têm consciência da questão ambiental e que a missão e valores da IES refletem o caráter socioambiental, porém conforme aduzido, não são expressos objetivos estratégicos anuais da instituição ou de sua mantenedora em relação ao processo de gestão e responsabilidade socioambiental e nem orçamento anual para equidade desta vertente.

No critério 7 referente aos Recursos Humanos, o processo de acolhimento, treinamento e capacitação dos funcionários não se apoia em um programa de Gestão de Recursos Humanos que aborde o conhecimento ou sensibilização acerca da questão socioambiental. Conforme assinado por Freire; Botelho e Nunes (2001),

Disponível em: https://www.nucleodoconhecimento.com.br/contabilidade/diretrizesdo-mec 
- Balanço Social poderia ser uma ferramenta útil para integração das informações sociais, ambientais e econômicas que poderiam contribuir com o posicionamento estratégico da IES.

No critério 8 que reporta a Contabilidade, não existe até o momento o registro de fatos de natureza ambiental nas demonstrações contábeis, somente no aspecto orçamentário. Inexiste ainda Relatório de Sustentabilidade ou similares. Os custos ambientais não são abordados de forma a auxiliar na tomada de decisão, conforme orientado pela ONU. (UNCTAD/ISAR, 1998)

No critério 9 na Auditoria Ambiental, por não existir um programa formal não há a realização de uma auditoria de gestão ambiental e ou responsabilidade socioambiental, porém há o acompanhamento das licenças e processos ambientais por um profissional formado em engenharia. Tais aspectos são criticados por May (2005); Deegan (2017). Vale destacar que Deegan (2017) aborda a necessidade de melhorar a informação contábil no que tange a questão socioambiental.

Vale destacar que os estudos apontados no quadro 6, em quase vinte publicações diferentes, que utilizam a metodologia SICOGEA para aferição da sustentabilidade os resultados são em sua maioria classificados como de sustentabilidade regular a muito boa. Assim os resultados encontrados na IES são discrepantes em relação aos achados dos demais estudos realizados pela Professora Pfitscher e seus coautores $(2008,2009,2010,2011,2013)$

Conforme definido no roteiro metodológico, os aspectos ambientais levantados foram a gestão dos resíduos; energia; matéria-prima; gestão das águas e efluentes; gestão de pessoas e emissões. O propósito deste objetivo é detalhar iniciativas adotadas pela instituição e potencialidades de forma a cruzar as informações complementares fornecidos pelos critérios do SICOGEA encontrados nos resultados supracitados.

De acordo com os dados coletados e indicados no Quadro 7 as questões mais críticas que envolvem potenciais melhorias são: destinação dos resíduos 
hospitalares; análise periódica da qualidade da água extraída do poço artesiano; tratamento do esgoto e a questão do possível risco de contaminação dos lençóis freáticos existentes no subsolo da IES e verificados nas caracterizações ambientais encontradas nos processos de licenciamento ambiental e outorga de água em função capacidade das fossas sanitárias da instituição. Os resultados aqui apresentados podem ser associados aos estudos de Keunecke; Uhlmann, Pfitscher (2012) e Pierri (2011) para instituições de ensino.

Há que se destacar que outros estudos devem ser realizados para que os dados referentes ao risco de contaminação sejam verificados, porém vale destacar que um dos maiores custos da instituição é com o esvaziamento das fossas, uma vez que a universidade não possui um sistema de tratamento dos resíduos internamente. Tendo em vista que existem tratamentos alternativos para os efluentes de fossas sanitárias, as linhas anuais de financiamento de pesquisa poderiam privilegiar estudos quanto aos riscos de contaminação e quanto ao tratamento destes. Atualmente existem linhas de financiamento bancárias que possuem taxas de juros mais atrativas para o financiamento de atividades que tenham como intuito a redução do impacto ambiental e esta seria uma alternativa a ser avaliada pela IES.

Quadro 07 - Aspectos Ambientais e Potencialidades

Aspectos Levantados

- Gestão dos Resíduos - a coleta é terceirizada e a IES tem um projeto de implantação de um galpão de integrado ao Sistema de Gestão separação de resíduos junto aos Ambiental que contemple diversas órgãos ambientais. Já possui projeto esferas e que aborde a reciclagem e protocolado junto ao órgão ambiental destinação adequada dos resíduos. para construção de galpão de separação de resíduos e destinação adequada do resíduo de saúde.

Aspectos a serem potencializados

- Gestão dos resíduos - implantação de um programa de educação ambiental 
- Energia - energia é comprada via - Campanha Contínua de uso racional mercado livre e distribuída pela da energia elétrica e implantação de empresa de energia estadual que fontes alternativas tais como energia cobra somente 0 serviço da solar; distribuição, o que possibilita a economia de recursos.

- Matéria-Prima - a aquisição de - Sistema de Gestão de Custos materiais não possui critérios integrado com os aspectos ambientais, socioambiental conforme aduzido no seleção de fornecedores segundo SICOGEA critérios socioambientais.

- Auditoria Interna dos contratos existentes; Critérios socioambientais na seleção de fornecedores e produtos.

- Gestão das Águas e efluente- A IES -Gestão das Águas - realização da possui outorga de água e capta suas análise periódica da água coletada para águas de um sistema de poço o consumo humano e se necessário o artesiano e as águas do sistema de tratamento da mesma; Realização de escoamento pluvial vão para o sistema Campanhas de Consumo consciente público. integrado a um Sistema de Gestão Ambiental.

- Implantação de um sistema de tratamento de efluentes.

- Pessoas - a gestão de pessoas não - Reestruturação do acolhimento dos possui um sistema de treinamento funcionários com a ambientação acerca voltados para área ambiental ou que da missão e programa de aborde a responsabilidade social responsabilidade social existente;

- Elaboração de cronograma de treinamentos que abordem a questão 
socioambiental.

- Emissões - não há nenhum programa - Emissão de Gases - sejam realizadas para a redução de emissões, porém a campanhas como um dia sem carro com IES possui uma boa arborização a parceria de cursos como 0 de especialmente em função dos projetos Educação Física que pode promover o de extensão como a Calourada dia da Pedalada, bem como a ampliação Universitária que realiza do projeto de plantio de espécies nativas semestralmente o plantio de mudas na IES e fora da instituição. para a realização de recomposição de paisagens que pode ser realizado em parceria com a Secretaria Municipal de Meio Ambiente e os cursos locais.

- Cálculo da pegada ecológico da IES, o qual possibilita saber a média de emissão de $\mathrm{CO} 2$ e a realização da compensação de emissão dos GEE's Gases de Efeito Estufa.

Fonte: Elaborado pelos Autores

Deste ponto em diante serão apresentados o levantamento da legislação federal ambiental incidente sobre a IES e a as normas e Legislação Federal de Educação Superior. No que tange a avaliação das leis ambientais federais incidentes na instituição foram verificados o Licenciamento Ambiental LEI № 6.938, DE 31 DE AGOSTO DE 1981(Política Nacional de Meio Ambiente a outorga do uso da água Lei 9433 de 1999 (Lei das Águas) e Gestão dos Resíduos Sólido - Lei 12.305 de 2010 (Política Nacional de Resíduos Sólidos).

Neste sentido constatou-se que a IES possui licenciamento ambiental vigente emitido, possui ainda a outorga de uso da água, pois a captação se dá via poço artesiano, porém no que se refere a gestão dos resíduos sólidos, a IES aguarda a autorização para a construção da unidade de separação e não há destinação 
adequada dos resíduos hospitalares. Destaca-se ainda que se verificou a exposição pública do alvará de funcionamento e da licença do corpo de bombeiros atualizada. Ainda no aspecto normativo a Lei 10.861 expressa em Brasil (2004a), regulamentada pelo Decreto 5.773/06 e Portaria número 92/16, que institui os instrumentos de avaliação das IES exigidos pelo MEC foram verificados sete aspectos conforme apontamentos abaixo:

1. ACESSIBILIDADE - Condições de acesso às pessoas que apresentam deficiência ou mobilidade reduzida, de acordo com o disposto na CF/88, Art. 205, 206 e 208, na Lei $N^{\circ} 10.098 / 2000$, na Portaria $N^{\circ} 3.284 / 2003$, na NBR 9050/2004, da ABNT e nos Decretos $N^{\circ}$ 5.296/2004, No 6.949/2009, $\mathrm{N}^{\circ}$ 7.611/2011. (BRASIL1988, 2004, 2009, 2011, 2003). Possui condições arquitetônicas que contemplam a acessibilidade tais como rampas, informações em braile, banheiro, balcões, pias adaptadas a cadeirantes, porém não há registros de treinamento dos funcionários e professores neste aspecto. Não foi identificado a disponibilização de cadeiras de rodas para pessoas com dificuldade de locomoção;

2. DIREITO DO AUTISTA - Proteção dos Direitos da Pessoa com Transtorno do Espectro Autista, conforme Disposto na Lei $N^{\circ}$ 12.764, de 27 de dezembro de 2012. . (COSTA, 2013). Possui e está em conformidade, porém não se tem claro qual o calendário de atividades e ações realizadas durante o ano;

3. CONTROLE SOCIAL - Comissão de Controle Social - (COLAPS), disposto na Portaria № 1.132 de 2/12. Possui e está em conformidade, porém não se tem claro qual o calendário de atividades e ações realizadas durante 0 ano (BRASIL 2012f)

4. RELAÇÕES ETNICO RACIAIS - Diretrizes Curriculares Nacionais Educação das Relações Étnico-raciais e para o Ensino de História e Cultura AfroBrasileira, Africana e Indígena, Lei № 9.394/96, com a redação dada pelas Leis № 10.639/2003 e № 11.645/2008, Resolução CNE/CP № 1/2004, parecer CNE/CP № 3/2004. (BRASIL 1996, 2003, 2004, 2008. O currículo da IES aborda em todos os cursos a vertente em sua ementa a vertente 
étnico racial, ambiental e de direitos humanos, porém o Programa de Responsabilidade Social não possui orçamento/financiamento voltado para esta vertente na IES, de modo que se evidencia a desarticulação entre o ensino, pesquisa e extensão nestes aspectos.

5. EDUCAÇÃO AMBIENTAL - Lei de educação ambiental, Nº 9.795/1999, Decreto № 4.281/2002 e Resolução CNE/CP № 2/2012. (BRASIL 1999, 2002, 2012a). O currículo da IES aborda em todos os cursos a vertente em sua ementa a vertente étnico racial, ambiental e de direitos humanos, porém o Programa de Responsabilidade Social não possui orçamento/financiamento voltado para esta vertente na IES, de modo que se evidencia a desarticulação entre o ensino, pesquisa e extensão nestes aspectos.

6. DIREITOS HUMANOS - Diretrizes Nacionais para a Educação em Direitos Humanos, conforme disposto no Parecer CNE/CP N 8, de 06/03/2012, que originou a Resolução CNE/CP No 1, de 30/05/2012. . (BRASIL 2012b, BRASIL, 2012c)O currículo da IES aborda em todos os cursos a vertente em sua ementa a vertente étnico racial, ambiental e de direitos humanos, porém o Programa de Responsabilidade Social não possui orçamento/financiamento voltado para esta vertente na IES, de modo que se evidencia a desarticulação entre o ensino, pesquisa e extensão nestes aspectos.

7. DESENVOLVIMENTO SUSTENTÁVEL - Desenvolvimento Nacional Sustentável, conforme disposto no Decreto $N^{\circ} 7.746$, de 05/06/2012 que trata das compras sustentáveis e seleção de fornecedores por critérios socioambientais. . (BRASIL 2012d) Apesar de ser uma lei voltada para compras no setor público, está no elenco de aspectos a serem verificados pelo instrumento de avaliação do MEC junto as IES. A IES em questão não possui ações neste sentido, conforme observado pela metodologia SICOGEA.

Podemos constatar a conformidade legal com o cumprimento da legislação educacional em seus aspectos socioambientais requeridos pelo SINAES. Contudo, verificamos a desconexão destas políticas com as práticas de forma integrada. As IES não são obrigadas a apresentarem relatórios de sustentabilidade em padrões 
praticados nacionais e internacionalmente. Está previsto a política de educação ambiental e do desenvolvimento sustentável no âmbito do PDI, contudo, este desenvolvimento sustentável limita-se a disciplina apresentada nas estruturas curriculares. A missão reflete o desenvolvimento sustentável, porém o orçamento, as compras, seleção de fornecedores e prática de gestão de materiais, gestão das águas, resíduos e emissões não refletem o posicionamento da IES. Os indicadores estratégicos indicam o direcionamento das metas para o alcance dos indicadores econômicos como EBITDA e não incluem objetivos que visem a minimização dos impactos oriundos das suas práticas.

\section{CONSIDERAÇÕES FINAIS}

O objetivo do trabalho foi analisar potenciais fatores a serem aprimorados sob o enfoque do sistema contábil de gestão ambiental e da conformidade legal socioambiental para com o Ministério da Educação (MEC). Conforme aponta o desenho metodológico, foi levantado o índice de sustentabilidade da instituição que foi avaliado como fraco, de acordo com a metodologia SICOGEA. Observa-se que apesar de haver uma visão acerca da importância de um Sistema de Gestão Socioambiental pelos dirigentes, não existe efetivamente um Programa de Responsabilidade Socioambiental orientado por metas, plano de ação, monitoramento e ações corretivas para o gerenciamento dos processos socioambientais. Existem políticas e os objetivos de responsabilidade socioambiental no Plano de Desenvolvimento Institucional, porém estes não possuem um programa de execução e orçamento para tal, o que limita o seu desenvolvimento.

A IES atende aos requisitos institucionalizados pelo MEC. Neste ponto desvela-se um aspecto para futuras pesquisas: se o SICOGEA classificou a organização como sustentabilidade fraca e ao mesmo tempo a IES atendo aos requisitos de Responsabilidade Socioambiental do MEC. Verifica-se um espaço de possíveis discussões e investigações neste ponto que poderiam questionar sobre quais são os pontos convergentes e divergentes entre os dois instrumentos. Poderia ser 
questionado em futuros estudos se existem possibilidades de melhorar 0 instrumento de avaliação do MEC (SINAES) no que tange aos aspectos socioambientais.

Este estudo, apesar de preliminar, indica que existem pontos passíveis de melhoria na legislação federal no tange ao cumprimento dos requisitos socioambientais da instituição em análise. As IES não têm por responsabilidade a evidenciação de relatórios de sustentabilidade, detalhando suas práticas. As políticas do PDI como visto nesta IES, não se concretizam nas ações em termos mais amplos, somente na oferta de disciplinas isoladas para conformidade da legislação sem passar pela revisão das tomadas de decisão refletidas no seu orçamento, compras, definição de fornecedores, monitoramento das ações e melhoria contínua das suas práticas. Outras oportunidades de melhoria são relativas à saúde das pessoas que trabalham e convivem na instituição no que se refere ao tratamento do esgoto, destinação de resíduos hospitalares, monitoramento da água e avaliação do risco de contaminação nos lençóis freáticos.

Como limitação do estudo, apontamos a escassez de literatura para discutir a aplicação da legislação socioambiental no âmbito do Sistema Nacional de Avaliação do Ensino Superior - SINAES. Outra limitação se deve ao fato de que estes resultados especialmente no que tange ao sistema SICOGEA não serem generalizáveis.

As implicações da pesquisa apontam para melhoria do sistema de gestão orçamentária, de compras, e gestão dos aspectos que implicam no consumo dos recursos naturais (energia elétrica, água, resíduos e emissões) além da necessidade de integração das políticas com as práticas e indicadores de gestão. Estas reflexões em torno das estratégias e práticas da instituição implicam em um olhar mais crítico no âmbito da legislação e da avaliação (SINAES) federal socioambiental incidente sobre a educação superior. Este último ponto poderá ser aprimorado em investigações posteriores. 


\section{REFERÊNCIAS}

ASSOCIAÇÃO BRASILEIRA DE NORMAS TÉCNICAS. NBR 16001. Responsabilidade social:sistema da gestão - requisitos. Brasil: ABNT, 2004.

ASSOCIAÇÃO BRASILEIRA DE NORMAS TÉCNICAS. NBR 9050: Acessibilidade a edificações, mobiliário, espaços e equipamentos urbanos. Rio de Janeiro: ABNT, 2015.

BACELO, Jerusa; UHLMANN, Vivian Osmari; PFITSCHER, Elisete Dahmer; SOUZA, Maíra Melo de. 2011.Sustentabilidade Ambiental em Condomínios: utilização do método sicogea para avaliar os aspectos e impactos ambientais em um condomínio residencial. Revista Catarinense da Ciência Contábil. Disponível em:<http://www.redalyc.org/articulo.oa?id=477548340006> ISSN 1808-3781. Acesso em $7 / 11 / 2016$.

BALDISSERA, Beatriz Maria; ALVES, Dayane; FARIAS, Sueli; MARIAN, Sérgio; PFITSCHER, Elisete Dahmer; BORGES, Thaiane Flor. 2008. Análise da Sustentabilidade Ambiental na Empresa Lavanderia Ecológica. In: 2ํㅡㅁ Congresso UFSC de Iniciação Científica em Contabilidade, 2008. FLORIANOPOLIS: UFSC, 2008. v. 1.0 p. 56-57. Disponível em: http://dvl.ccn.ufsc.br/congresso_internacional/anais/2CCF/index.htm. Acesso em:20/06/2016.

BARAKAT, Simone Ruchdi, BOAVENTURA, João Maurício Gama, POLO, Edilson Fernandes 2017. Alinhamento Estratégico da Responsabilidade Social Corporativa: um estudo de caso no setor bancário brasileiro. REAd - Revista Eletrônica de Administração, $\quad$ ISSN 1980-4164. Disponível emhttp://www.redalyc.org/articulo.oa?id= 401151139009. Acesso em 20/05/2016

BRASIL, Lei №. "10.861 de 14 de abril de 2004. Institui o Sistema Nacional de Avaliação da Educação Superior-SINAES e dá outras providências. 2004a. 
BRASIL. Decreto № 3.298, de 20 de dezembro de 1999. Brasília, 1999. Disponível em: <Disponível em: http://www.planalto.gov.br/ccivil_03/decreto/d3298.htm >. Acesso em: 06 jun. 2015. Disponível em: http://www.planalto.gov.br/ccivil_03/decreto/d3298.htm Acesso em 20/05/2016

BRASIL. Portaria No 1.132. Institui a Comissão de Controle Social - (COLAPS). $2012 f$

BRASIL. Presidência da República.CasaCivil. Subchefia para Assuntos Jurídicos. Lei oㅜ 11.645, de 10 de março de 2008. Altera a Lei oㅜ 9.394, de 20 de dezembro de 1996, modificada pela Lei № 10.639, de 9 de janeiro de 2003, que estabelece as diretrizes e bases da educação nacional, para incluir no currículo oficial da rede de ensino a obrigatoriedade da temática "História e Cultura Afro-Brasileira e Indígena”. Brasília, DF: D.O.U., 11 mar. 2008.

BRASIL. Plano Nacional das Diretrizes Curriculares Nacionais para a Educação das Relações Étnico-raciais e para o Ensino de História e Cultura Afro-brasileira e Africana. Brasília: SECAD; SEPPIR, jun. 2008

BRASIL. Lei Federal nำ 10.639, de 09 de Janeiro de 2003. Altera a Lei n. 9.394, de 20 de dezembro de 1996 (estabelece as diretrizes e bases da educação nacional, para incluir no currículo oficial da rede de ensino a obrigatoriedade da temática história e cultura afro-brasileira, e dá outras providências). 2003

BRASIL. Lei $\mathrm{n}^{\circ}$. 10.098, de 19 de dezembro de 2000. Estabelece normas gerais e critérios básicos para a promoção da acessibilidade de pessoas portadoras de deficiência ou com mobilidade reduzida, e dá outras providências. Diário Oficial [da]República Federativa do Brasil, Brasília, DF, 20 dez. 2000

BRASIL. DECRETO № 5.296 DE 2 DE DEZEMBRO DE 2004, que regulamenta as Leis $\mathrm{n}^{\circ} 10.048$, de 8 de novembro de 2000 , que dá prioridade de atendimento às pessoas que especifica, e 10.098, de 19 de dezembro de 2000, que estabelece normas gerais e critérios básicos para a promoção da acessibilidade das pessoas 
portador as de deficiência ou com mobilidade reduzida, e dá outras providências. 2004.

BRASIL. Diretrizes Curriculares Nacionais para a Educação das Relações ÉtnicoRaciais e para o Ensino de História e Cultura Afro- Brasileira. Brasília. 2004.

BRASIL. Orientações e Ações para a Educação das Relações Étnico-raciais. Brasília: MEC; SECAD, 2006.

BRASIL. Lei ํํ 10.436, de 24 de abril de 2002. Dispõe sobre a Língua Brasileira de Sinais - Libras e dá outras providências. Diário Oficial da União República Federativa do Brasil: Poder Legislativo, Brasília, DF, 24 abril 2002. Disponível em: <Disponível em: http://www.jusbrasil.com.br/legislacao/99492/lei-de-libras-lei-10436-02\#art0 >. Acesso em: 02 maio 2014.

BRASIL. Ministério da Educação. Portaria № 3.284, de 7 de novembro de 2003. Brasília, 2003.

BRASIL Decreto $n^{\circ}$ 5.296. Trata das condições arquitetônicas que contemplam a acessibilidade. 2004

BRASIL Decreto $n^{\circ}$ 5.773. Dispões sobre o PDI e as diretrizes filosóficas, pedagógicas, gerenciais e operacionais das instituições conforme a Lei 10.861 de 2004. 2006

BRASIL Decreto $n^{\circ}$ 6.949. Dispõe sobre condições de acessibilidade nas instituições. 2009

BRASIL. Ministério da Educação. SECADI. Política Nacional de Educação Especial na Perspectiva da Educação Inclusiva. 2008.

BRASIL. Política Nacional de Educação Especial na Perspectiva da Educação Inclusiva Brasília, 2007. Disponível em: <Disponível em: 
http://peei.mec.gov.br/arquivos/politica_nacional_educacao_especial.pdf >. Acesso em: 11 jun. 2015.

BRASIL. Resolução № 1 de 2002, que institui as Diretrizes Operacionais para a Educação Básica nas Escolas do Campo; Parecer CNE/CEB no. 36, de 2001; Lei no 9.224, de 1996, que institui o FUNDEF; art. no. 28, da LDBEN. 2002

BRASIL. Decreto ํo 7.611 , de 17 de novembro de 2011. Dispõe sobre a educação especial, o atendimento educacional especializado e dá outras providências. Diário Oficial da União: República Federativa do Brasil: Poder legislativo, Brasília, DF, 17 nov. 2011. Disponível em: <http://www.planalto.gov.br/ccivil_03/_Ato20112014/2011/Decreto/D7611.htm>. Acesso em: 12 jan. 2015.

BRASIL. Lei no 13.146, de 6 de julho de 2015. Institui a Lei Brasileira de Inclusão da Pessoa com Deficiência. Estatuto da Pessoa com Deficiência. Brasília, 2015.

BRASIL. INSTITUTO NACIONAL DE ESTUDOS E PESQUISAS EDUCACIONAIS ANÍSIO TEIXEIRA - INEP. 2014. Documentos e Legislação: instrumento de avaliação de instituições de ensino superior. Disponível em http://portal.inep.gov.br/web/guest/documentos-e-legislacao17. Acesso em 20/11/2015.

BRASIL. MINISTÉRIO DA EDUCAÇÃO.2014. Portaria n॰92 de janeiro de 2014 que dispõe sobre o Instrumento de Avaliação das Instituições de Ensino Superior no Brasil. Disponível em <https://goo.gl/KWjmXe. Acesso em 14/12/2015.

BRASIL. MINISTÉRIO DA EDUCAÇÃO. CONSELHO NACIONAL DE EDUCAÇÃO CONSELHO PLENO. RESOLUÇÃO № 2, DE 15 DE JUNHO DE $2012\left({ }^{*}\right)$ Estabelece as Diretrizes Curriculares Nacionais para a Educação Ambiental.2012a

BRASIL. MINISTÉRIO DA EDUCAÇÃO CONSELHO NACIONAL DE EDUCAÇÃO. Conselho Nacional de Educação. Parecer no 8. Diretrizes Nacionais para a Educação em Direitos Humanos. 2012b 
BRASIL. MINISTÉRIO DA EDUCAÇÃO. CONSELHO NACIONAL DE EDUCAÇÃO CONSELHO PLENO RESOLUÇÃO № 1, DE 30 DE MAIO DE 2012. Estabelece Diretrizes Nacionais para a Educação em Direitos Humanos. 2012c

BRASIL . Decreto ํㅜ 7.746, de 05 de junho de 2012. Regulamenta o art. o da Lei no 8.666, de 21 de junho de 1993, para estabelecer critérios, práticas e diretrizes para a promoção do desenvolvimento nacional sustentável nas contratações realizadas pela administração pública federal, e institui a Comissão Interministerial de Sustentabilidade na Administração Pública - CISAP. 2012d.

BRASIL. MINISTÉRIO DO MEIO AMBIENTE.2000. Agenda XXI. Disponível em $<$ https://mma.gov.br>. Acesso em 14/12/2015.

BRASIL. RESOLUÇÃO № 2, DE 15 DE JUNHO DE 2012, que estabelece as Diretrizes Curriculares Nacionais para a Educação Ambiental. DOU no 116, Seção 1, págs. $70-71$ de 18/06/2012. 2012e

BRASIL. Lei n. 9795. Dispõe sobre a educação ambiental. Política Nacional de Educação Ambiental. Brasília, 1999.

BRASIL. LDB. Lei 9.394. Dispõe sobre a Lei de Diretrizes e Bases da Educação Nacional. 1996. Disponível em< www.planalto.com.br. >. Acesso em 15 de novembro de 2017.

B3 - Brasil, Bolsa, Balcão. Bolsa Brasileira de Valores. Índices de Sustentabilidade da B3. São Paulo. 2021.

BURRITT, Roger L.; HAHN, Tobias; SCHALTEGGE, Stefan. Towards a Comprehensive Framework for Environmental Management Accounting - Links Between Business Actors and Environmental Management Accounting Tools. 2000. Disponível em :http://onlinelibrary.wiley.com/wol1/doi/10.1111/j.18352561.2002.tb00202.x/abstract. Acesso em 20/05/2016 
BRUNDTLAND, Gro Harlem, and Nosso Futuro Comum. "Relatório Brundtland." Our Common Future: United Nations (1987).

CARROLL, Archie B., 1979, "A Three Dimensional Conceptual Model of Corporate Social Performance", in Academy of Management Review, Vol. 4, Issue 4, pp. 497505.

COSTA, Ulisses. Autismo no Brasil, um grande desafio: a história da luta de um pai e a origem da Lei Federal no 12.764, Lei Berenice Piana 1. ed. Rio de Janeiro: WAK. 2013

CUNHA, Ana Melissa; LIMONGI, Bernadete; CEOLLATO, Cristiane Fernandes; PFITSCHER, Elisete Dahmer; CASAGRANDE, Maria Denize Henrique; MARIAN, Sérgio. 2008. Sustentabilidade Ambiental: Um Estudo de Caso Numa Estação de Tratamento de Água e Esgoto em Santa Catarina - Brasil. In: XII Congresso Contabilidade e Auditoria - A Contabilidade na Era Global, 2008, Aveiro - Portugal: Universidade de Aveiro - ISCA Instituto Superior de Contabilidade e Administração, 2008. v. 1. p. 988-1004. Disponível em: http://nemac.ufsc.br/files/2012/11/casan.pdf. Acesso em: 20/06/2016.

CUNHA, Carla Thaís Nascimento da; PFITSCHER, Elisete Dahmer; ALBERTON, Luís; NUNES, João Paulo de Oliveira; NERES, Denize. 2008. A Gestão da Prefeitura Municipal de Florianópolis Quanto ao Meio Ambiente com o Auxílio da Contabilidade e Controladoria Ambiental. In: SIMPÓSIO ANPAD. BRASÍLIA: ANPAD, 2008. Disponível em: http://www.anpad.org.br/ anpad/eventos.php?cod_evento=5\&cod_edicao_subsecao $=404 \&$ cod_evento_edicao=40\&cod_edicao_trabalho=9726. Acesso em: 20/06/2016.

DEEGAN, Craig. 2017. Twenty-five years of social and environmental accounting research within Critical Perspectives of Accounting: Hits, misses and ways forward Journal Title: Critical Perspectives on Accounting Cross.Volume 43, p. 65-87. Disponível 
emhttp://www.sciencedirect.com/science/article/pii/S1045235416300284?via\%3Dihu b. Acesso em 30/08/2017.DOI:https://doi.org/10.1016/J.CPA.2016.06.005>

ELKINGTON, John. 2012. Sustentabilidade, canibais com garfo e faca. São Paulo: M. Books do Brasil.

FERREIRA, Aracéli Cristina de Souza. 2003.Contabilidade ambiental: uma informação para o desenvolvimento sustentável. São Paulo: Atlas.

FERREIRA, Aracéli Cristina de Souza. 2007. Contabilidade ambiental: informação para o desenvolvimento sustentável.2. ed. Atlas.

FERREIRA, Elaine; CUNHA, Jorge; ROSSETTO, Carlos Ricardo. 2008. Adaptação estratégica e gestão ambiental: Um estudo das mudanças organizacionais em uma indústria de fundição da região de Joinville - SC. In: ENGEMA- X Encontro Nacional de Gestão Empresarial e Meio Ambiente. 9 a 12 nov. 2008, Porto Alegre. Anais do Encontro Nacional de Gestão Empresarial e Meio Ambiente. Porto Alegre, p. 140149.

FREIRE, Fátima de Souza, BOTELHO, Ducineli Régis, e NUNES, Florisval Mareco. "Balanço Social Abrangente: ferramenta contábil eficaz para mensuração do papel social das empresas." Revista Brasileira de Contabilidade, CFC, Brasília: ano XXX n $130,2001$.

FREITAS, Claudio Luiz de; SILVEIRA, Eduardo; RICHARTZ, Fernando; PFITSCHER, Elisete Dahmer; BRENNER, Kátia; ZOLET, Patrícia Elmisan. 2008. Análise de Sustentabilidade Ambiental: Um Estudo de Caso na Vonpar Refrescos S.A. In: $2^{\circ}$ Congresso UFSC de Iniciação Científica em Contabilidade, 2008. Florianópolis: UFSC. $\quad$ v. $1 . \quad$ p. 57-59. Disponível em: http://dvl.ccn.ufsc.br/congresso/anais/2CCF/20080809224414.pdf Acesso em: 20/06/2016. 
GALLON, Alessandra Vasconcelos; NASCIMENTO, Cristiano do; PFITSCHER, Elisete Dahmer. 2008. A Gestão da Cadeia Produtiva de Moluscos Catarinense e Suas Limitações Operacionais. In: XI Simpósio de Administração da Produção, Logística e Operações Internacionais, 2008, São Paulo. XI SIMPOI, 2008. Disponível em: http://nemac.ufsc.br/files/2012/11/aquicultura.pdf. Acesso em: 20/06/2016.

GASPARETTO, Valdirene; MARTINS, Fracini; PFITSCHER, Elisete Dahmer; GALLON, Alessandra Vasconcelos. 2008. Percepção dos Formandos de Ciências Contábeis 2007/2 das Universidades da Grande Florianópolis Sobre Governança Corporativa. Revista Catarinense da Ciência Contábil - CRCSC - Florianópolis, v.7, n.21, p.85 - 101, ago. /nov. 2008. In: $2^{\circ}$ Congresso UFSC de Controladoria e Finanças, 2008, Florianópolis. Disponível em: http://www.redalyc.org/html/4775/477549011007/. Acesso em: 20/06/2016.

GRAY, Rob. 2005. Tomando uma visão longa do que sabemos agora sobre responsabilidade social e ambiental e relatórios". Revista eletrônica Teoria da organização radical. Disponível em http://www.mngt.waikato.ac.nz/ejrot [Google Scholar]. Acesso em 22/07/2016.

INSTITUTO ETHOS DE RESPONSABILIDADE SOCIAL - ETHOS. 2016. Missão, $\begin{array}{lllll}\text { visão } & \text { e } & \text { objetivos. } & \text { Disponível em }\end{array}$ http://www1.ethos.org.br/EthosWeb/pt/29/o_que_e_rse/o_que_e_rse.aspx. Acesso em 09/03/2016.

KEUNECKE, Gabriella Rossi, UHLMANN, Vivian Osmari, PFITSCHER, EliseteDahmer.2012. Análise da Sustentabilidade Ambiental de uma Instituição de Ensino Segundo o Sistema Contábil Gerencial Ambiental - Geração 2.Revista Gestão Universitária na América Latina - GUAL. Disponível em: $<$ http://www.redalyc.org/articulo.oa?id=319327516010> ISSN. Acesso em $20 / 05 / 2016$

LEFEBVRE, Henri.1966. Para compreender o pensamento de Karl Marx. Lisboa: Edições 70.

RC: 91385

Disponível em: https://www.nucleodoconhecimento.com.br/contabilidade/diretrizesdo-mec 
LIMONGI, Bernadete; PFITSCHER, Elisete Dahmer; KREMER, Bruna Valéria; CASAGRANDE, Maria Denize; Henrique; NUNES, João Paulo de Oliveira. 2008.Contabilidade Ambiental como instrumento de auxílio na gestão: aplicação parcial do SICOGEA em uma Instituição de Ensino. In:12ํN NEMAC - Congresso do Núcleo de Estudos sobre Meio Ambiente e Contabilidade da UFSC. Florianópolis, $\begin{array}{lllllll}2008 . & v & 1 . & \text { p. } & 56-57 & \text { Disponível } & \text { em }\end{array}$ http://nemac.paginas.ufsc.br/files/2012/11/escola.pdf. Acesso em 20/03/ 2016.

LIMONGI, Bernadete; KREMER, Bruna Valéria; CASAGRANDE, Maria Denize Henrique; PFITSCHER, Elisete Dahmer; NUNES, João Paulo O. 2008. A Contabilidade Ambiental como Instrumento de Auxílio na Gestão: Aplicação Parcial do SICOGEA em uma Instituição do Ensino. In: XII Congresso Contabilidade e Auditoria - A Contabilidade na Era Global, 2008, Aveiro - Portugal: ISCA Instituto Superior de Contabilidade e Administração, 2008. v. 1. p. 1082-1098. Disponível em: http://nemac.ufsc.br/files/2012/11/escola.pdf. Acesso em: 20/06/2016.

LOUREIRO, Carlos Frederico; VIÉGAS, Aline. 2007. Complexidade e Dialética: por uma busca de novos elementos na tradição da crítica ambiental diante dos desafios da educação ambiental. Rio Grande, Ambiente e Educação, n. 12. p. 27-45.

MAZZIONI, Sady; TINOCO, João Eduardo Prudêncio; OLIVEIRA, Antônio Benedito Silva. 2007. Proposta de um modelo de balanço social para fundações universitárias. BASE: Revista de Administração e Contabilidade da Unisinos. São Leopoldo, v. 4. n. 3, p. 274-285.

MAY, P. H.(Org.) Economia Do Meio Ambiente: Teoria E Prática. 3. ed. LTC Gen: Rio de Janeiro, 2018.

MELO NETO, Francisco Paulo de; BRENNAND, Jorgina Melo. 2004. Empresas Socialmente Sustentáveis: o novo desafio da gestão moderna. Rio de Janeiro: Qualitymark. p. 28-49. 
NASCIMENTO, Cristiano do; GALLON, Alessandra Vasconcelos; GASPARETTO, Valdirene; PFITSCHER, Elisete Dahmer. 2008. Aplicação da Contabilidade de Custos na Atividade Aquícola. In: XV Congresso Brasileiro de Custos, 2008, Curitiba: EDUGRAF, 2008. v. 1. p. 5-21. Disponível em: http://nemac.ufsc.br/files/2012/11/4cristianoplanejamento.pdf. Acesso em: 20/06/2016.

NASCIMENTO, Artur Roberto do; SANTOS, Ariovaldo dos; SALOTTI, Bruno, MÚRCIA, FernandoDal-Ri.2009. Disclosure Social e Ambiental: Análise das Pesquisas Científicas Veiculadas em Periódicos de Língua Inglesa. Contabilidade $\begin{array}{lllll}\text { Vista } & \& & \text { Revista. } & \text { Disponível }\end{array}$ :<http://www.redalyc.org/articulo.oa?id=197015470002> ISSN 0103-734X. Acesso em 30/11/2016.

NUNES, João Paulo de Oliveira; LIMONGI, Bernadete; PFITSCHER, Elisete Dahmer; CARRASCOZA, Henrique Schramm. 2008. Controle e Gestão Ambiental Por Meio da Contabilidade: Um Estudo de Caso em uma Fábrica de Pranchas de Surfe. In: X Encontro Nacional de Gestão Empresarial e Meio Ambiente, 2008, Porto Alegre: ENGEMA, 2008. v. 1. p. 239-240. Disponível em: http://engema.org.br/XENGEMA/X-ENGEMA.pdf Acesso em: 20/06/2016.

ORGANIZAÇÃO das Nações Unidas (ONU). Divisão para o Desenvolvimento Sustentável das Nações Unidas. EUA, 2001.

OTTONELLI, Janaina; SILVA, Mariano J. L. 2011. A importância das medidas multidimensionais de pobreza para a administração pública: um exercício em Palmeira das Missões (RS). Rev. Adm. Pública, v. 45, n. 2, p. 837-862.

OTTONELLI, Janaina; SILVA, Mariano J. L. Pobreza multidimensional nos municípios da região Nordeste. Rev. Adm. Pública, v. 48, n. 5, p. 1253-1279, set./out. 2014 
PIERRI, Ricardo; FREY, Irineu Afonso; PFITSCHER, Elisete Dahmer. 2011. Gestão estratégica e ambiental: estudo de uma universidade comunitária. Anais XII Congresso Internacional de Custos. Punta del Este, Uruguay.

PFITSCHER, Elisete Dahmer; ARAUJO, Ana Paula Linhares de; VICENTE, Ernesto Fernando Rodrigues; NUNES, João Paulo de Oliveira. 2009. Gestão dos Aspectos e Impactos Ambientais em um Condomínio Com o Envolvimento da Contabilidade Ambiental. Revista eletrônica Catarinense da Ciência Contábil- CRCSC. v.2. n. 22. p. 9-26. Florianópolis, SC, Brasil. ISSN: 2237-7662, ISSN: 1808-3781Disponível: http://revista.crcsc.org.br/index.php/CRCSC/article/view/1075/1008. Acesso em: 20/06/2016.

PFITSCHER, Elisete Dahmer; LEONARDO, Marcelo de Ataíde; VICENTE, Ernesto Fernando Rodrigues; GALLON, Alessandra Vasconcelos; SILVA, Guilherme Júlio da. 2008. Sustentabilidade Social Empresarial: Estudo de Caso em uma Geradora de Energia Elétrica. In: XXVIII Encontro Nacional de Engenharia de Produção, 2008, Rio de Janeiro. Disponível em: http://nemac.ufsc.br/files/2012/11/2enegep2008_TN_STP_079_550_11288.pdf. Acesso em: 20/06/2016.

PFITSCHER, Elisete Dahmer; NUNES, João Paulo de Oliveira; FURTADO, Ana Paulo Peixoto; ROSA, Fabrícia Silva da. 2008. Um Aporte da Contabilidade a Gestão Ambiental: Estudo de Caso em uma Empresa do Ramo de Cerâmica. In: $2^{\circ}$ Congresso UFSC de Controladoria e Finanças, 2008, Florianópolis: UFSC, 2008. v. 1.

p. 52-53.

Disponível

em:

http://dvl.ccn.ufsc.br/congresso_internacional/anais/2CCF/index.htm . Acesso em: 20/06/2016.

PFITSCHER, Elisete Dahmer.2004. Gestão e sustentabilidade através da contabilidade e controladoria ambiental: estudo de caso na cadeia produtiva de arroz ecológico. Florianópolis, 252 p. Tese (Doutorado em Engenharia da Produção) Programa de Pós- Graduação em Engenharia da Produção, Universidade Federal de Santa Catarina. 
RAMALHO, Luana de Souza, UHLMANN, Vivian Osmari; PFITSCHER, Elisete Dahmer, RABELO, EdílsonCitadin.2010. Avaliação da sustentabilidade dos aspectos e impactos ambientais de serviços odontológicos: um estudo de caso. Enfoque: Reflexão Contábil 2010, Disponível em:<http://www.redalyc.org/articulo.oa?id=307126111006> ISSN 1517-9087

RAUPP et al. O Perfil do Profissional da Contabilidade do Ramo de Serviço Público. In: XII Congresso Contabilidade e Auditoria - A Contabilidade na Era Global, 2008, Aveiro - Portugal: ISCA Instituto Superior de Contabilidade e Administração, 2008. v. 1. p. 1679-1698. Disponível em: http://nemac.ufsc.br/files/2012/11/publico.pdf. Acesso em: 20/06/2016.

RIBEIRO, Maísa de Souza. 2005.Contabilidade Ambiental. São Paulo: Saraiva.

RICHARTZ, Fernando; FREITAS, Claudio Luiz. Análise de Sustentabilidade Ambiental em uma indústria de bebidas: um enfoque no processo produtivo. Revista Contemporânea de Contabilidade. 2009

ROSA, Fabrícia Silva da; PFITSCHER, Elisete Dahmer; SILVA, Cintia Bernadete; VIEIRA, Eleonora Milano Falão; SILVA, Guilherme Julio da. Responsabilidade SocioAmbiental Analisada em uma Rede de Supermercados com Auxílio do SICOGEA. In: XV Congresso Brasileiro de Custos, 2008, Curitiba: ABC - Associação Brasileira de Custos, 2008, ISSN 2358-856X. 2008

ROSA, Fabrícia Silva da; PFITSCHER, Elisete Dahmer; STEIGER, Marciani Maria; NUNES, João Paulo de Oliveira; SILVA, Guilherme Júlio da. 2008. A Implantação do SICOGEA - Sistema Contábil Gerencial Ambiental em um Hospital. In: XV Congresso Brasileiro de Custos, 2008, Curitiba: ABC - Associação Brasileira de Custos, 2008, ISSN 2358-856X. Disponível em: https://anaiscbc.emnuvens.com.br/anais/article/view/1255. Acesso em: 20/06/2016.

SARDEIRO, Luciana da Silva Moraes. SOUZA, Paulo Vitor Souza de. A Normatização Contábil Sob O Enfoque Ambiental Mediada Pela Auditoria $\mathrm{Na}$ 
Mineração: Uma Análise Crítica Na Perspectiva Miltoniana E Freireana. Revista Científica Multidisciplinar Núcleo do Conhecimento. Ano 06, Ed. 05, Vol. 02, pp. 40 70. Maio de 2021. ISSN: 2448-0959, Link de acesso: https://www.nucleodoconhecimento.com.br/contabilidade/normatizacao-contabil. Acesso em: 15/05/2021.

SARDEIRO, L. D. S. M., \& BILHIM, J. A. de F. Normatização Contábil dos Riscos Climáticos: um ensaio sobre a atuação no interesse público do IASB. Brazilian Journal of Development, Ed. 7 vol. 5, 45050-45078. 2021

SEIFFERT, Mari Elizabete Bernardini. "Gestão Ambiental: Instrumentos." Esferas de Ação e Educação Ambiental, Atlas (2007).

SOUSA, Gustavo Rugoni de; TAVARES, Débora Reis; PFITSCHER, Elisete Dahmer. 2008. Análise Sócio-Econômica de uma das Maiores Empresas Aéreas Brasileira na Crise do Setor de 2006 A 2007. In: XII Congresso Contabilidade e Auditoria.2008, Aveiro- Portugal: ISCA - Universidade de Aveiro, 2008. v. 1. p. 18791903.

SOUZA, Paula; PFITSCHER, Elisete Dahmer. 2013.Gestão e Sustentabilidade Ambiental: Estudo Em Um Órgão Público Do Estado De Santa Catarina. Revista de Contabilidade \& Controladoria; Curitiba Vol. 5, (Sep/Dec 2013): p.8-32.

STAROSKY FILHO, Loriberto, PFITSCHER, Elisete Dahmer, FREITAS, Claudio Luiz de.2011. Sustentabilidade ambiental e responsabilidade social voluntária: estudo em um escritório de contabilidade. Enfoque: Reflexão Contábil.

UNCTAD/ISAR - United Nations Conference on Trade and Development/ Intergovernmental Working Group of Experts on International Standards of Accounting and Reporting. Environmental Financial Accounting and Reporting at the Corporate level. United Nations: Geneva, 1998. 
VEGINI, Danúbia; PFITSCHER, Elisete Dahmer; NUNES, João Paulo de Oliveira; ROSA, Fabrícia da Silva. 2008. Contabilidade e Auditoria Ambiental Como Forma de Gestão: Um Estudo de Caso de um Hospital. Revista Catarinense da Ciência Contábil - CRCSC - Florianópolis, v.7, n.21, p.23 - 40, ago./nov. 2008. In: 18 Congresso Brasileiro de Contabilidade, 2008, Gramado - RS. Disponível em: http://www.redalyc.org/html/4775/477549011003/. Acesso em: 20/06/2016.

Enviado: Maio, 2021.

Aprovado: Julho, 2021. 